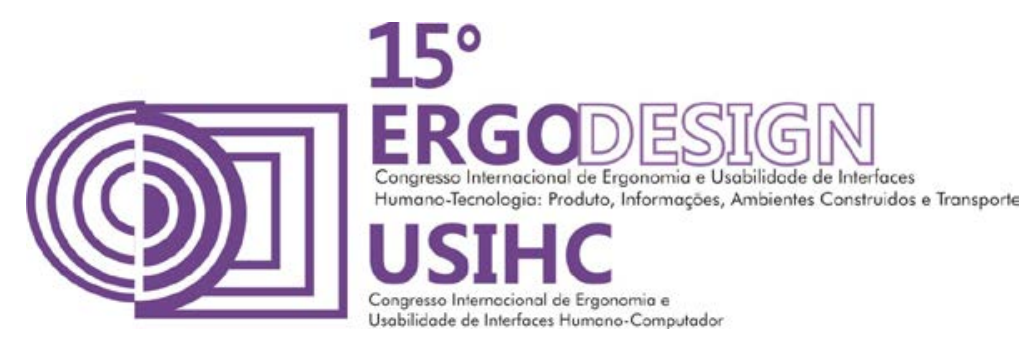

\title{
ERGONOMIA E INDÚSTRIA DE CONFECÇÃO: OTIMIZANDO O SETOR DE COSTURA DE UMA EMPRESA DO AGRESTE PERNAMBUCANO
}

\author{
BARROS, Bruno (1); \\ FARIAS, Rafaella (2); \\ CERQUEIRA, Raul (3) \\ (1) Universidade Federal de Pernambuco, Mestre \\ e-mail:barros bruno@hotmail.com \\ (2) Universidade Federal de Pernambuco, Bacharela \\ e-mail:fariasrafaella@yahoo.com.br \\ (2) Universidade Federal de Pernambuco, Bacharela \\ e-mail:raul.gcerqueira@yahoo.com.br
}

\begin{abstract}
RESUMO
Considerando a importância econômica do Pólo de Confecções do Agreste para o estado de Pernambuco, sendo o mesmo uma das principais fontes de geração de emprego local (devido ao seu quantitativo de empresas formais e informais), foi realizada uma avaliação ergonômica no setor de costura de uma confecção de fardamentos de uma cidade. Para tanto, seguiu-se a Metodologia Ergonômica do Ambiente Construído-MEAC. A avaliação permitiu identificar os índices, níveis, valores e resultados acerca da iluminação, ventilação e aeração, temperatura, vibração, ruído e cor do setor de costura e atividade humana, que, quando comparados com as bibliografias, referências, normas e leis existentes, puderam revelar condições físico-ambientais deficientes, as quais podem ser prejudiciais à saúde e segurança dos funcionários do setor de costura da empresa.
\end{abstract}

\section{ABSTRACT}

Considering the economic importance of the Wasteland Clothes Pole for the state of Pernambuco, the same being one of the main sources of employment generation due to their amount of formal and informal enterprises, an ergonomic evaluation was performed in the sewing industry for a construction of uniforms in Caruaru, Pernambuco following the Built Environment Ergonomics Methodology-MEAC. The evaluation identified the indices, levels, values and results about the lighting, ventilation and aeration, temperature, vibration, noise and color of the sewing industry, which when compared to the bibliographies, references, standards and existing laws could prove physical conditions disabled-environment, which can be harmful to health and safety of employees in the sewing department of the company. 


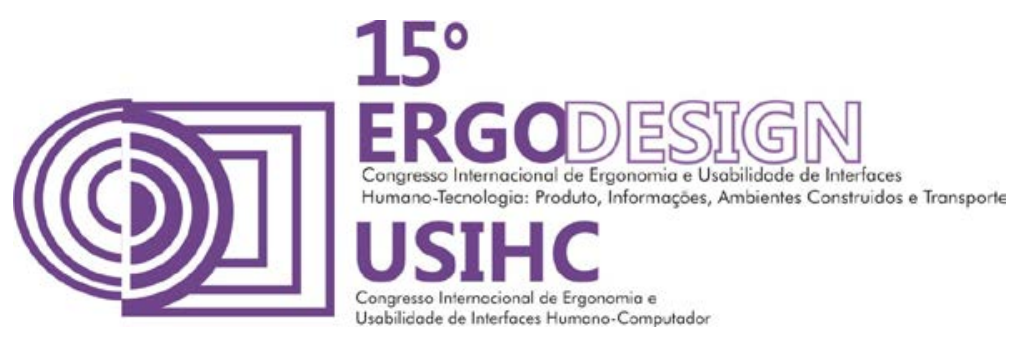

\section{INTRODUÇÃO}

As indústrias de confecções do vestuário e similares representam um quantitativo significativo para a cidade de Caruaru e principalmente para o estado, considerando que segundo o SEBRAE (2012) existiam cerca de 1.666 empresas até o ano de 2002 em todo o estado. Até o ano de 2008, o MTE (2009 apud DIEESE,2010) afirma que as empresas do setor têxtil nos municípios de Caruaru, Toritama e Santa Cruz do Capibaribe, principais cidades do Pólo de Confecções do Agreste, totalizavam cerca de 2.030 empresas. As mesmas possuem grande participação na economia do estado assim como, são responsáveis por gerar empregos para homens e mulheres.

A hipótese é a de que os ambientes de trabalho de uma confecção podem vir a apresentar deficiências em alguns fatores como: ambientes aparentemente pequenos, mal ventilados com pouca iluminação, máquinas amontoadas acarretando circulações estreitas com obstáculos impedindo um fluxo contínuo, equipamentos e elementos de apoio mal distribuídos e condições de trabalhos inadequadas. Reis (2012 apud Aquino et al., 2012), afirma que o setor apresenta um ambiente de trabalho que pode vir a oferecer riscos a saúde do trabalhador, sendo assim, alvo de preocupações.

Sendo assim, a pesquisa buscou realizar uma avaliação ergonômica em um setor de costura de uma indústria de confecção no município de Caruaru, voltada para a fabricação de roupas profissionais (uniformes). Especificamente, buscou-se analisar a atividade humana e aferir os valores de iluminância, ventilação, temperatura, vibração e ruído no ambiente de trabalho dos costureiros, e por fim, analisar as características cromáticas de todo o setor, para então propor melhorias que possam tornar o ambiente de trabalho adequado às necessidades dos funcionários do mesmo.

\section{FUNDAMENTAÇÃO TEÓRICA}

\subsection{O Mercado Nacional e Local de Confecção}

O município de Caruaru, localizado no Agreste de Pernambuco com área aproximada de 921 $\mathrm{Km}^{2}$ e uma população estimada de 298.501 habitantes, está situada a $140 \mathrm{Km}$ da capital Recife. Suas principais fontes de renda são; o comércio, destacando-se a Feira de Caruaru, o turismo, tendo como principais pontos na cidade o Alto do Moura e a Feira de Artesanatos, e as indústrias de confecções (IBGE, 2013).

Até o ano de 2002, o SEBRAE (2010) contabilizou cerca de 1.666 indústrias voltadas para a fabricação de artigos do vestuário em geral, no estado de Pernambuco. É importante frisar que esses dados caracterizam o quantitativo de empresas legalizadas e, desde então, tal número de confecções formais vem crescendo não somente no estado, mas especificamente nas cidades em que a produção de roupas e similares faz parte do seu desenvolvimento econômico. 


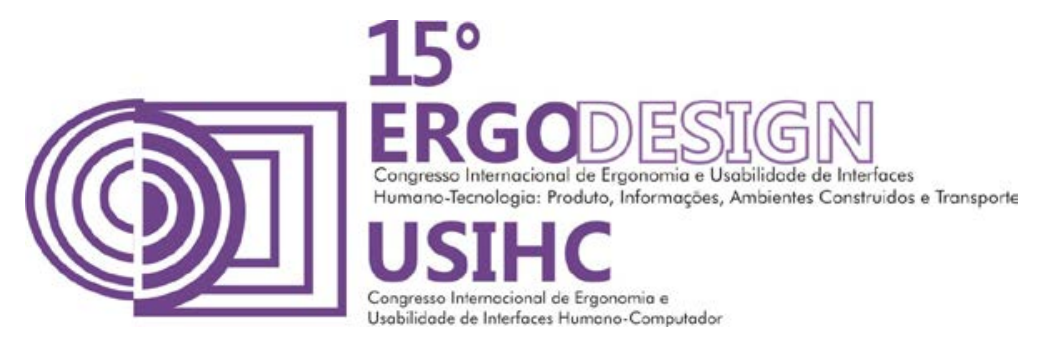

De acordo com o MTE (2009 apud DIEESE, 2010), entre os anos de 2006 a 2008, foi possível observar um crescimento de aproximadamente $13 \%$ dos estabelecimentos formais e $16 \%$ dos trabalhadores do setor têxtil da cidade de Caruaru, apresentando uma média de 59,9\% e $61,9 \%$, respectivamente. Porém, analisando o ano de 2002 e 2008, observa-se o crescimento considerável do número de estabelecimentos industriais voltado para o setor têxtil, sendo que foram contabilizadas no ano de 2008, 2.030 empresas somente nas cidades de Caruaru, Santa Cruz do Capibaribe e Toritama, onde possivelmente esse quantitativo venha a ser ainda maior com o acréscimo de outras cidades do estado.

No Brasil, o quantitativo de confecções destinadas à fabricação de fardamentos vem crescendo consideravelmente nos últimos anos, chegando a representar uma parcela relevante para a economia do país, e isso se deve possivelmente ao aumento da procura pelos mesmos, seja pelos empresários ou por seus funcionários. A Associação Brasileira de Desenvolvimento Industrial (2010 apud SEBRAE, 2012), afirma que, em 2008, o segmento de uniformes profissionais no Brasil contava com 1.700 empresas e movimentava cerca de $\mathrm{R} \$ 3,5$ bilhões/ano no País. O segmento cresceu mais de $80 \%$ em produção e cerca de $50 \%$ em valor na última década, apesar da falta de regulamentação e da observação de normas técnicas do setor.

\subsection{A Ergonomia do Ambiente Construído}

A Ergonomia do Ambiente Construído ou como também é chamada, Ergonomia Ambiental, tem como preocupação a forma como se dá a integração entre o ser humano e o ambiente, segundo os aspectos sociais, culturais, organizacionais e psicológicos (VASCONCELOS, VILLAROUCO e SORAES, 2009). É importante se conhecer os fatores que fazem parte de um ambiente construído, a fim de propor melhorias que possam vir a beneficiar no bem estar do funcionário e no melhor desempenho de suas atividades.

Com relação à análise de um posto de trabalho, lida (2005) diz que, quando se trata de uma unidade mais simples, onde o ser humano interage apenas com uma máquina, é importante realizar um estudo das interações que acontecem entre o ser humano, a máquina e o ambiente do trabalho. A ergonomia do ambiente construído busca estudar essa relação entre o homem e seu local de trabalho, assim como os equipamentos usados nas atividades nele desenvolvidas, a fim de proporcionar um ambiente adequado às necessidades do seu usuário.

Villarouco e Andreto (2008), afirmam que a diversidade de atividades e diversidade humana se for consideradas, pode segundo as características do ambiente, facilitar ou dificultar a realização das atividades, e que o conceito de ambiente de trabalho não pode ser aplicado totalmente, devido a esses ambientes mudarem segundo seu tipo de atividade, ou seja, tal conceito pode vir a auxiliar na avaliação de ambientes similares.

\subsection{Aspectos Normativos Reguladores do Ambiente}

lida (2005), afirma que é importante o uso da iluminação adequada para realização das tarefas, pois se sabe que a iluminância em excesso ou escassez facilita o aparecimento da fadiga 


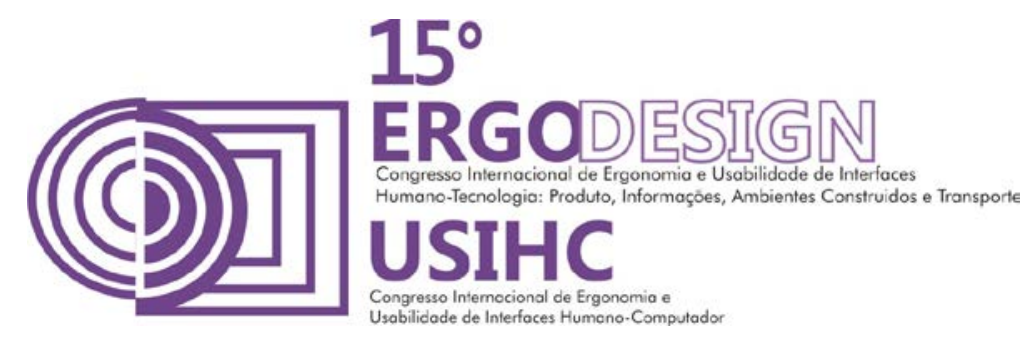

visual. Outro problema que pode ocorrer é o ofuscamento, que ocorre com o excesso de luz, janelas ou locais com excesso de brilho, causando uma redução de eficiência visual (Maia 2012).

A NBR5382 estabelece como se deve averiguar a iluminância de interiores em áreas retangulares, por meio da iluminância média sobre um plano horizontal, derivado da iluminação comum. Já a NBR 5413/1992 diz que o índice de iluminância adequado para uma sala de aula deve estar entre 200, 300 e 500Lux. Mas para alunos menores de 40 anos de idade, cuja atividade em sala não requer velocidade e precisão deve ser considerado o valor mais baixo, 200LuX.

O Conforto térmico é um estado mental que reflete a satisfação com o ambiente térmico que envolve a pessoa. Se o balanço de todas as trocas de calor, a que está submetido o corpo, for nulo e a temperatura da pele e suor estiverem dentro de certos limites, pode-se dizer que 0 homem sente o conforto térmico (ASHRAE, 1985 apud LAMBERT, 1997). O conforto térmico também pode ser o dificultador da realização de atividades, pois além de causar desconfortos existe uma perda de energia maior que em um ambiente em condições térmicas confortáveis.

Para lida (2005), uma zona de conforto térmico apropriada aos padrões brasileiros tem temperatura efetiva entre $20^{\circ}$ e $24^{\circ} \mathrm{C}$, com umidade relativa de 40 a $60 \%$, com a velocidade do ar na ordem $0,2 \mathrm{~m} / \mathrm{s}$ e as diferenças de temperatura em um mesmo ambiente não devem ser maiores a $4^{\circ} \mathrm{C}$. A NR-17 diz que diz que o índice de temperatura efetiva deve estar entre $20^{\circ} \mathrm{e}$ $23^{\circ} \mathrm{C}$ e que a velocidade do ar não deve ser superior a $0,75 \mathrm{~m} / \mathrm{s}$.

No que diz respeito as sensações cromáticas, a Norma ISO 11064-6 indica que as paredes devem ter acabamentos com cores frias, poupando acabamentos escuros ou luminosos em amplas superfícies; a variação de cores e texturas deve existir para favorecer o relaxamento; deve ser evitado grandes contrastes entre mobiliários e equipamentos.

O limite de nível de ruído diário em que um indivíduo pode permanecer exposto sem danos a audição é de $80 \mathrm{~dB}(\mathrm{~A})$, caso esse limite seja excedido, há um risco de perda auditiva, ao qual varia de pessoa para pessoa. Nos ambientes de trabalho que superem o nível máximo permitido, devem ser feitas intervenções, a fim de reduzir os níveis de ruídos, mas em alguns casos, ainda é necessária a adoção de equipamentos de proteção individual, especificamente, protetores auriculares (BRASIL, 2013b).

Os danos que as vibrações podem provocar ao homem dependem das frequências que compõem as mesmas, sendo as vibrações de baixa frequência (de 1 a $80-100 \mathrm{~Hz}$ ) as mais prejudiciais e as de alta frequência (acima de $100 \mathrm{~Hz}$ ) menos prejudiciais, pois são absorvidas pelo corpo, não gerando ressonância. Desse modo, os problemas mais comuns em decorrência de vibração localizadas são: danos neurológicos, de ordem vascular e osteoarticular e muscular, podendo ocorrer adormecimento leve e intermitente, formigamento ou os dois casos (CONSELHO E SEGURANÇA DO TRABALHO, 2011). 


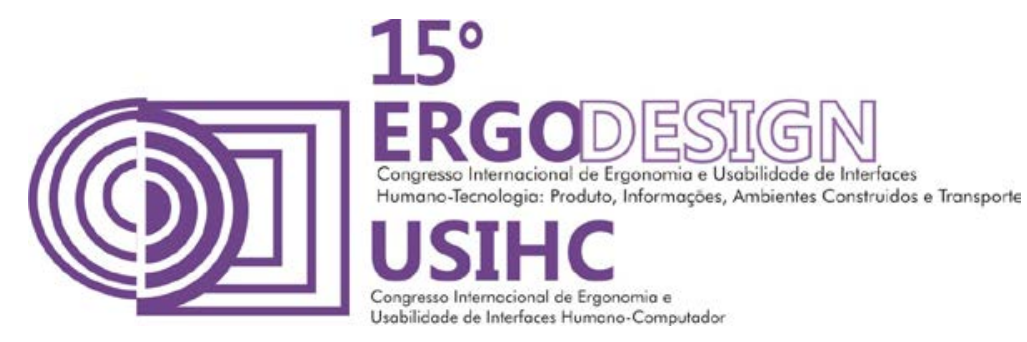

\section{PROCEDIMENTOS METODOLOGICOS ADOTADOS}

A metodologia utilizada na referente pesquisa foi a MEAC (Metodologia Ergonômica do Ambiente Construído), que é proposta por Villarouco (2009). A seleção desta metodologia seguiu o atendimento de requisitos como consistência cientificamente comprovada e abordagem de aspectos referentes não só à condicionantes ambientais, como também à percepção dos usuários.

A MEAC é compreendida em quatro etapas analíticas e duas conclusivas, sendo elas: a Análise Global do Ambiente; a Identificação da Configuração do Ambiental; a Avaliação do Ambiente em Uso, Percepção Ambiental do Usuário, Diagnóstico Ergonômico do Ambiente e Proposições Ergonômicas para o Ambiente. Para uma maior compreensão da metodologia utilizada em toda a pesquisa, a seguir são caracterizadas cada uma de suas etapas:

1. Análise Global do Ambiente: A Análise Global do ambiente consiste na fase inicial da pesquisa, onde se tem o primeiro contato com o ambiente estudado, o que possibilita ter ideia da configuração espacial do ambiente e se analisa as atividades desenvolvidas. A partir disso, se percebe os principais problemas e demandas que indicam a necessidade da intervenção. Possibilitando uma visão sistêmica do ambiente a partir do conhecimento dos materiais, do pessoal que usa o ambiente, do desperdício de tempo e equipamentos utilizados, dos fluxos, dos processos e produtos principais, para assim, entender o que é feito e como é feito o ambiente (Villarouco, 2009).

2. Identificação da Configuração Ambiental: Na fase de Identificação da Configuração do Ambiente, é estudada a análise da tarefa para conhecer as condições físico-ambientais. Através do conhecimento do trabalho realizado, das tarefas desenvolvidas, das características que devem conter os postos e estação de trabalho, maquinário, equipamentos e tecnologias utilizadas. (Villarouco, 2007).

3. Avaliação do Ambiente em Uso no Desempenho das Atividades: Na terceira fase Villarouco (2009) recomenda que seja feita uma Avaliação do Ambiente em Uso no desenvolvimento das atividades, para saber o quanto facilitador e dificultador se torna o ambiente no momento da realização das tarefas. Nessa fase, analisa-se o desenvolvimento das atividades focando no espaço construído, com o objetivo de verificar a interferência positiva ou negativa do espaço construído no desempenho das atividades.

4. Análise da Percepção do Usuário: Na quarta e última fase chamada de Percepção Ambiental, a autora diz que é necessário fazer um estudo da percepção que os usuários têm do ambiente que utiliza. Para se entender melhor a percepção do usuário, é importante utilizar o auxilio da psicologia ambiental como ferramenta auxiliar para identificar as características de caráter mais cognitivo e perceptual.

Por fim, a MEAC é concluída com mais 2 etapas, a 5. Diagnóstico Ergonômico do Ambiente e 6. Proposições Ergonômicas para o Ambiente, as quais irão apresentar os resultados das avaliações e expor recomendações de alteração direcionadas ao ambiente em questão. 


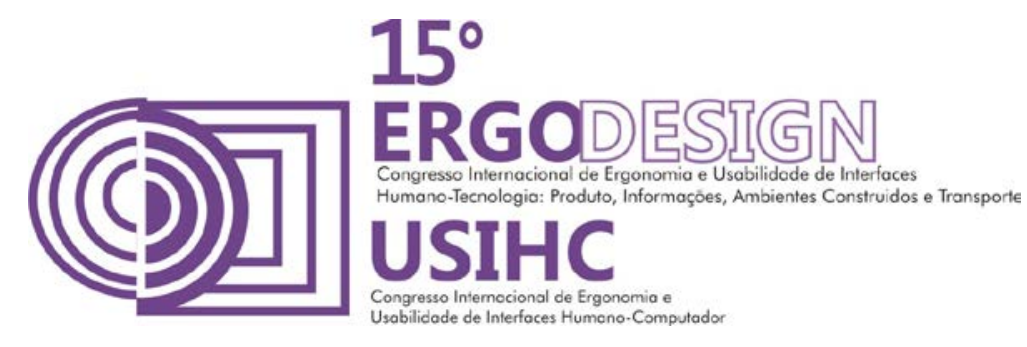

\section{DISCUSSÃO E APRESENTAÇÃO DOS RESULTADOS}

Quanto à iluminação, são poucos os focos de iluminação natural, sendo os mesmos ainda insuficientes para gerar um iluminamento que venha a contribuir com o melhoramento da visibilidade das costureiras na realização de suas atividades. Outro ponto que contribui na deficiência de iluminação natural está no fato de que as maiores aberturas, que permitem maior passagem de luz, estão afastadas dos postos de trabalho das costureiras. O poço permite uma passagem de luz quase nula, devido as suas dimensões pequenas e ao muro que sobe para o pavimento superior. Por fim, a abertura mais próxima permite pouca passagem de luz também devido as suas dimensões pequenas e principalmente, a sua distância até o chão, ficando acima de dos 2 metros.

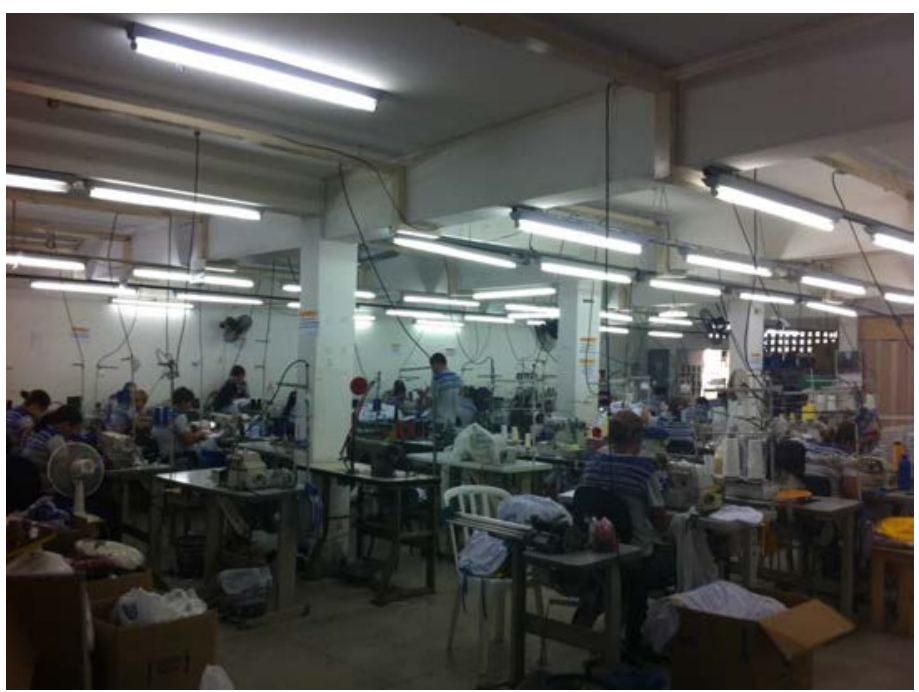

Figura 1: Ambiente de costura no momento da análise

Desse modo, a NBR 5413 determina no item 5.3.53 a iluminância adequada para os setores da indústria de vestuário, especificamente, para o setor de costura, permanecendo o índice entre 750 a 1500. No entanto, o resultado de iluminância média do salão de costura da empresa, obtido por meio das medições realizadas no local com o luxímetro no período da manhã, é de 438,77 lux, demonstrando um índice de iluminância muito abaixo do valor mínimo determinado pela norma.

Quanto à ventilação, são poucas as aberturas observadas no local, fator esse agravado pelo dimensionamento e posicionamento das mesmas, o que não beneficia os funcionários em receber os ventos naturais vindos de fora da edificação, na altura dos mesmos sentados. A localização das janelas e portas que funcionam como aberturas que permitem a passagem dos ventos, também não favorece uma circulação de ventos por todos os locais do salão, ficando alguns pontos sem receber ventilação natural. A quantidade de ventiladores de teto e de parede é insuficiente para suprir a ventilação em todo o setor, sendo alguns postos beneficiados e outros não. Dentro deste contexto, a NR 17 determina que para ambientes de trabalho onde as 


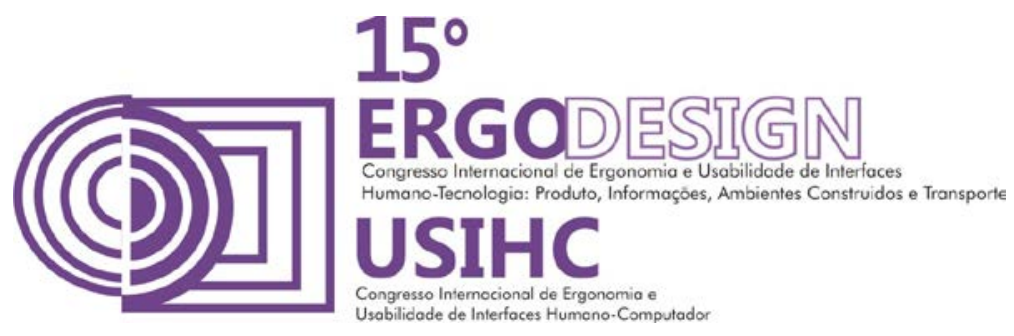

atividades executadas exijam atenção constante, a velocidade do ar não pode ser superior a $0,75 \mathrm{~m} / \mathrm{s}$.

No entanto, os resultados obtidos a partir das medições no ambiente, a fim de verificar a presença e velocidade do vento que circula pelo mesmo foram:

- Centro do salão, próximo a um dos funcionários: $1.8 \mathrm{~m} / \mathrm{s}$;

- Extremidade do salão, próximo à janela, a um dos ventiladores de parede e de um dos funcionários: $3.4 \mathrm{~m} / \mathrm{s}$;

- Local de ventilação quase nula, próximo a um dos funcionários: $0.5 \mathrm{~m} / \mathrm{s}$.

Os resultados mostram que a ventilação no setor ultrapassa o limite determinado pela norma, exceto nos locais afastados de ventiladores e janelas. No entanto, mesmo um dos resultados permanecendo dentro do limite ideal estabelecido pela norma e os outros excedendo o mesmo, fazendo aparentar que o ambiente é bem ventilado, há reclamações por parte dos funcionários do setor com relação à ventilação do mesmo, caracterizando-a como deficiente.

Quanto à temperatura, o que ocorre com o setor de costura da confecção é que, quando o fator de insolação da fachada voltada para o salão é somado a pouca ventilação e a falta de aeração do ar no espaço, o ambiente adquire altas temperaturas, tornando o mesmo extremamente quente. O fardamento usado pelos funcionários também contribui para o seu desconforto relacionado à temperatura, isso porque muitas vezes o uso do mesmo não é controlado pela empresa, fazendo com que alguns funcionários optem por usar calça jeans com a camisa padrão da mesma (camisa de malha com manga curta) e tênis com meia.

Desse modo, a NR 17 determina que a temperatura ideal para ambientes construído, permanece entre $20^{\circ} \mathrm{C}$ a $23^{\circ} \mathrm{C}$. Contudo, os resultados obtidos a partir das medições no setor de costura, a fim de verificar a máxima (verão) e a mínima (inverno) temperatura do mesmo foram:

- Verão - no centro do salão, próximo a um dos funcionários: $27,8^{\circ} \mathrm{C}$;

- Verão - na extremidade do salão, próximo à fachada voltada para a rua e a um dos funcionários: $29,6^{\circ} \mathrm{C}$;

- Inverno - no centro do salão, próximo a um dos funcionários: $20^{\circ} \mathrm{C}$;

- Inverno - na extremidade do salão, próximo à fachada voltada para a rua e a um dos funcionários: $18,2^{\circ} \mathrm{C}$.

Os resultados mostram que no período do verão, as temperaturas ultrapassam os limites ideais determinados pela norma, tornando o ambiente extremamente quente e prejudicial à saúde dos trabalhadores. No entanto, no período de inverno, as temperaturas permanecem no limite ou pouco abaixo dos limites ideais determinados no referencial, porém não a ponto de tornarem o ambiente prejudicial à saúde dos costureiros. 


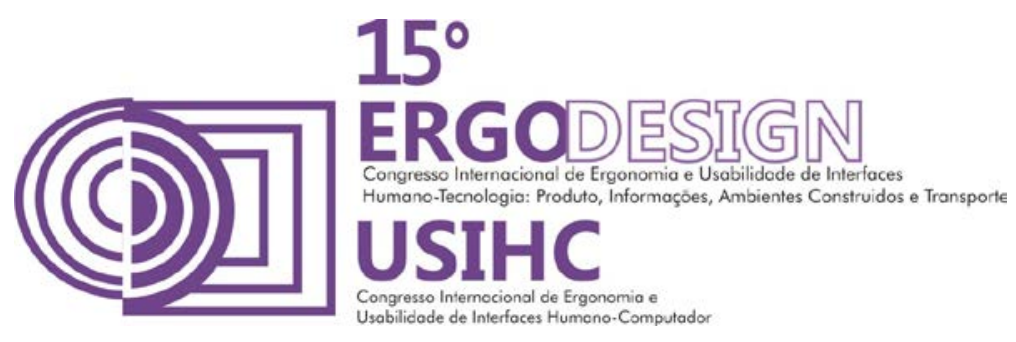

Quanto ao ruído, cada modelo de máquina emite um som (ruído) diferente, onde a máquina de casear ou caseadeira foi identificada como a que produz maior ruído, seguida da máquina reta eletrônica e de alguns ventiladores de parede. É importante também acrescentar que os funcionários do setor de costura da empresa possuem uma jornada de trabalho de 9 horas diária, com intervalos de 10 minutos nos períodos da manhã e tarde e 1 hora para o almoço, ou seja, durante 9 horas por dia os funcionários são expostos a diversas fontes de ruído sem intervalos consideráveis.

Neste sentido, a NR 15 determina que os trabalhadores podem permanecer expostos ao nível de ruído de até, $85 \mathrm{~dB}$ por no máximo, 8 horas. Os resultados obtidos a partir das medições no ambiente, a fim de verificar os níveis de ruído em diferentes pontos do mesmo, foram:

- Centro do salão, próximo ao ouvido de um dos funcionários: 75,3 dB;

- Extremidade do subsetor de brim, próximo à janela e ao ouvido de um dos funcionários: 74,5 $\mathrm{dB}$;

- Centro do subsetor de malha, próximo ao ouvido de um dos funcionários: 85,1 dB.

Os resultados mostram que o nível de ruído no salão, pode ultrapassar o limite do de 85 dB determinado pela norma, sendo agravado pelo tempo de exposição, já que os funcionários permanecem expostos ao ruído por 9 horas, ultrapassando o limite de 8 horas determinado pela norma. Desse modo, os resultados não estão de acordo com a norma, tornando assim, 0 ambiente prejudicial para a saúde auditiva dos funcionários. Porém, são fornecidos a todos os funcionários os protetores auriculares de três falanges semiesféricas de diâmetro crescente, no entanto, nem todos fazem uso dos mesmos todo tempo de trabalho.

Quanto à vibração, as máquinas são, sem dúvida, as maiores gerados de vibração no setor, algo que não é sentido no chão ou no ar, sendo somente perceptível no toque ou em contato direto com a máquina ou a bancada. Contudo, alguns costureiros e costureiras possuem prática e habilidade no desempenho de suas atividades, ocasionado que os mesmos não apoiam as mãos e nem os braços na máquina ou na bancada. A vibração é transmitida ao corpo dos funcionários por meio dos pés, através do pedal. É importante acrescentar que as máquinas quando ligadas, porém sem uso, possui uma vibração mais baixa, ao contrário de quando estão em uso.

Desse modo, a escala de Mercalli Modificada (MMI), a qual não possui unidade de medida, determina que a partir de 5.0, a vibração é considerada bastante forte. Os resultados obtidos a partir das medições nas máquinas, a fim de verificar o índice de vibração das mesmas foram: Máquina reta eletrônica: 6.6; Máquina reta mecânica: 7.2; Máquina overloque: 5.5; Máquina interloque: 5.8; Máquina de travete: 6.6.

Os resultados mostram que, os índices de vibração que acometem os funcionários, através de seus membros inferiores, são superiores ao limite de vibração prejudicial ao indivíduo, determinado pela escala. No entanto, foi observado que, os funcionários sofrem a incidência de vibrações pontuadas e não contínuas. 


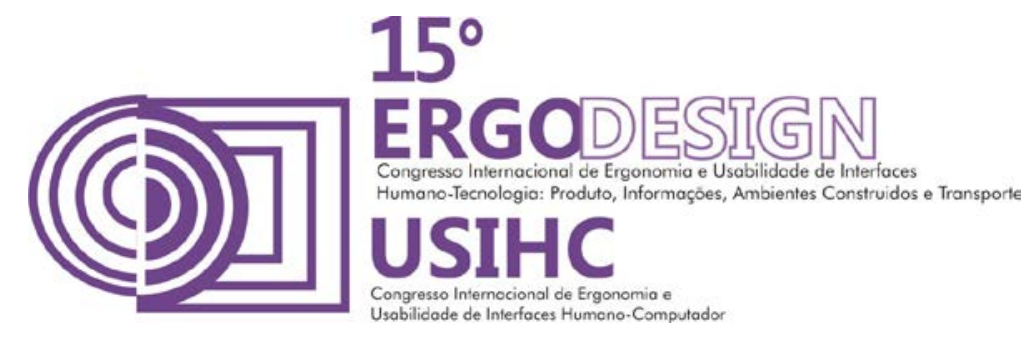

Quanto às características cromáticas, tanto as paredes como o teto do salão possuem somente uma cor, o branco neve fosco. A cor branca, como já mencionado no referencial, reflete $100 \%$ a luz, assim como, torna o ambiente mais claro, aparentemente maior, sereno e calmo. O piso de granilite na cor cinza contribui para deixar o ambiente mais escuro, no entanto, o mesmo possui uma rápida absorção d'água e boa aderência, contribuindo para a segurança dos funcionários.

Quanto à organização do espaço, há uma demanda maior de máquinas do que o ambiente pode comportar dessa forma, a falta de espaço e excesso de objetos propicia a criação de um local impróprio para o desenvolvimento das atividades, assim como, ajuda a obstruir as circulações. A falta de espaço também é percebida nos postos secundários, devido ao mesmo fator, o excesso de postos de trabalho no setor.

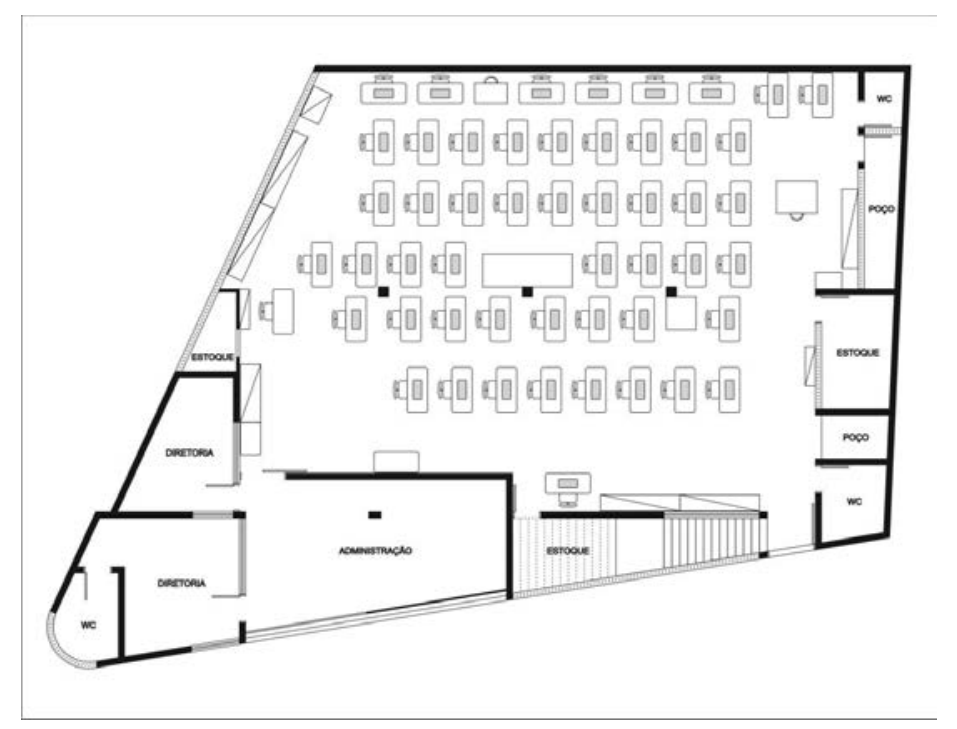

Figura 2: planta baixa e layout da fábrica no momento de análise

Com crescimento da empresa, o espaço atual é insuficiente para acomodar todas as máquinas e equipamentos de apoio, o que torna os postos de trabalhos com espaços reduzidos causando desconforto para os funcionários. A falta de planejamento é evidenciada pelos acessos inadequados, da proximidade dos banheiros ao salão, assim como também pela falta de banheiro masculino e distância entre os estoques, um dos fatores que ocasiona choque de fluxos.

Diante da demanda ergonômica no setor de costura da empresa, abaixo estão listadas as recomendações para adequação do ambiente construído e das atividades durante a pesquisa:

- Melhorar a iluminação do setor de costura de acordo com a NBR 5413;

- Adequar o sistema de iluminação ao tipo de atividade executada no ambiente de trabalho, revendo as instalações das luminárias e os tipos de lâmpadas;

- Adequar o sistema de ventilação ao setor de costura;

- Implantar equipamentos que permitam retirar o ar quente do ambiente; 


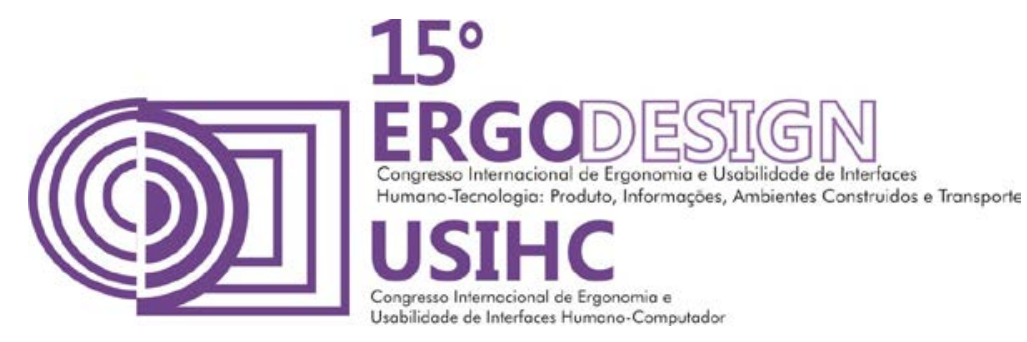

- Redimensionar as aberturas, permitindo a passagem de ar natural na altura dos funcionários sentados;

- Rever os materiais usados nas aberturas e mecanismos que permitam pouca passagem de ventos no inverno, sem prejudicar a segurança da edificação;

- Instalar mais ventiladores de tetos, permitindo maior área de ventilação;

- Procurar adquirir equipamentos e maquinários que emitam o menor ruído possível;

- Fornecer EPI's, especificamente, protetores auriculares que permitam proteger a audição dos funcionários segundo os níveis de ruído no ambiente, implementado juntamente, um programa que forneça informações e orientações aos funcionários da importância do uso do EPI;

- Fornecer aos funcionários, fardamento adequado às condições do ambiente construído e das atividades executadas no local, permitindo para os mesmos, conforto e segurança;

- Evitar fixar avisos ou cartazes nas paredes do setor, permitindo assim, maior reflexão da luz;

- Reorganizar o espaço, retirando os maquinários e mobiliários sem uso;

- Separar os postos principais (máquinas) dos postos secundários (mesas de apoio);

- Redimensionar as circulações entre as máquinas de modo a não causar estrangulamento de fluxos;

- Redimensionar os postos de trabalhos de modo a agrupar todos os elementos de apoio ao alcance do trabalhador sem prejudicar sua postura;

- Trocar as cadeiras dos funcionários por modelos que atendam as especificações da NR 17;

- Em caso de futuras reformas ou mudança de instalações, contratar profissionais especializados para realizar um projeto de ventilação, iluminação e layout adequados às necessidades da empresa e principalmente, dos funcionários.

\section{CONCLUSÕES E CONSIDERAÇÕES FINAIS}

A metodologia proposta para a realização da avaliação ergonômica do ambiente construído de costura, a MEAC, contribuiu consideravelmente para a avaliação das condições físicoambientais do setor de costura, permitindo identificar os fatores que interferem no bem estar dos usuários do ambiente, tais como: iluminação, ventilação e aeração, vibração, ruído, temperatura, características cromáticas do local e organização do espaço (layout, fluxos, postos de trabalho e acessibilidade).

A mesma permitiu ainda conhecer o ambiente de trabalho, assim como a maneira na qual as atividades reais são desenvolvidas no local, além de realizar as medições necessárias para constatação ou não das inadequações das condições ambientais do ambiente. A partir da metodologia, foi possível verificar como os funcionários do setor percebem seu ambiente, assim como os mesmos idealizam um ambiente para a realização de suas atividades, sendo possível identificar a partir disso, os fatores que incomodam mais e menos os trabalhadores. 


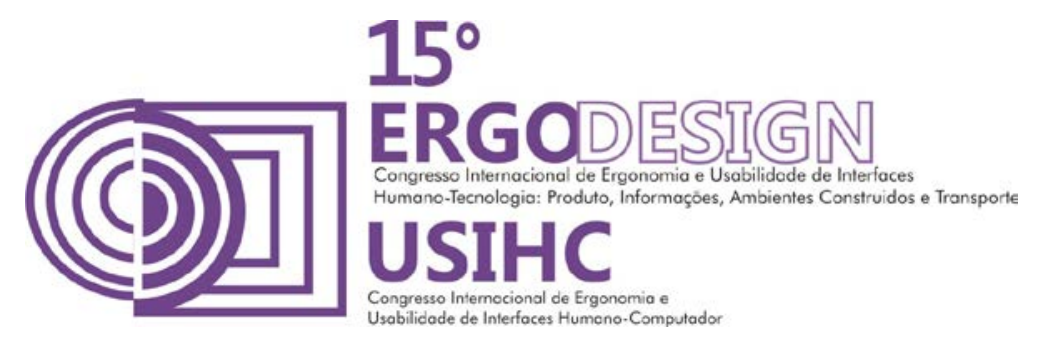

Através da avaliação ergonômica do ambiente construído e dos dados, valores e parâmetros apresentados no referencial teórico, foi possível constatar que todas as condições físicoambientais do setor de costura apresentavam deficiências, exceto os índices de vibração. Os resultados também demonstraram que alguns desses fatores tornam o ambiente de costura extremamente prejudicial à saúde e segurança dos usuários, alterando também, na forma e velocidade com que os mesmos executam as suas respectivas atividades.

É possível também, afirmar com base nos resultados, que os fatores relacionados à ventilação, iluminação, temperatura e organização do espaço são os condicionantes físico-ambientais que detém maior atenção e preocupação, considerando que o ambiente é mal ventilado, fazendo com que o mesmo permaneça com altas temperaturas durante o período de verão e somado a falta de espaço, torna o setor quente, desconfortável, prejudicial à segurança e a saúde, gerando insatisfação por parte dos usuários do mesmo. O ruído e as vibrações transmitidas pelas máquinas não interferem no desempenho das atividades dos funcionários, assim como os resultados obtidos mostram valores não prejudiciais, no caso da vibração, e pouco prejudiciais, no caso do ruído, onde o mesmo é solucionado com o uso de protetores auriculares.

Em resumo, os resultados permitiram identificar divergências em diversos aspectos físicos e ambientais no setor de costura da empresa, os quais necessitam de melhorias para, então, atender as necessidades daqueles que utilizam o mesmo. Sendo assim, torna-se necessária a realização de adequações na estrutura física do setor, assim como investir na melhoria dos sistemas de iluminação e ventilação.

Desse modo, espera-se que os resultados possam mostrar e alertar os proprietários da situação real das condições de trabalho de seus funcionários, fazendo com que os mesmos adotem medidas projetos que visem adequar o ambiente de trabalho as necessidades dos seus usuários, promovendo a qualidade de vida e humanizando o tratamento dos operários no ambiente de trabalho.

\section{REFERÊNCIAS BIBLIGRÁFICAS}

AQUINO, Danielly Silva de. et al. Análise da qualidade de vida no setor de costura de uma indústria de confecção. In: COMBREPRO 2011: Congresso Brasileiro de Engenharia de Produção, 1., 2011, Ponta Grossa.

ASSOCIAÇÃO BRASILEIRA DE NORMAS TÉCNICAS - NBR 10152: níveis de ruído para conforto acústico. Rio de Janeiro, 1987.4 p.

ASSOCIAÇÃO BRASILEIRA DE NORMAS TÉCNICAS - NBR 5413: iluminância de interiores. Rio de Janeiro, 1992. 13 p.

BRASIL. Fundacentro. Ruído. Disponível em: http://www.fundacentro.gov.br. Acesso em: 8 mar. 2013b.

BRASIL. Ministério do Trabalho e Emprego. 2007. NR 17 - Ergonomia (117.000-7). Disponível em:<http://www.mte.gov.br/legislacao/normas_regulamentadoras/nr_17.asp>. Acesso em: 11 set. 2012.

CONSELHO E SEGURANÇA DO TRABALHO. O que é vibração? 2011. Acesso em: http://conselhoeseguranca.blogspot.com.br. Acesso em: 27 mar. 2013. 


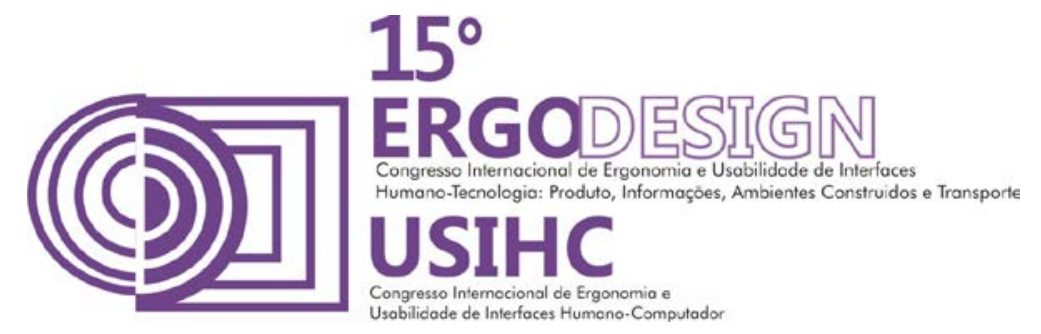

DIEESE - Departamento Intersindical de Estatística e Estudos Socioeconômicos. Relatório final: Diagnóstico do setor têxtil e de confecções de Caruaru e região. 2010. Disponível em: http://www.dieese.org.br. Acesso em: 17 nov. 2012.

IBGE - Instituto Brasileiro de Geografia e Estatística. IBGE Cidades: Dados gerais: Caruaru. Disponível em: http://www.ibge.gov.br. Acesso em: 17 ago. 2013.

IIDA, Itiro. Egonomia: projeto e produção. 2a edição. São Paulo: Edgard Blucher, 2005.

LAMBERT, Roberto, DUTRA, Luciano, PEREIRA, Fernando O. R. Eficiência Energética na Arquitetura. São Paulo: PW, 1997.

SEBRAE - Serviço Brasileiro de Apoio às Micro e Pequenas Empresas. Comece certo: indústria de confecção. 2004. pág. 5. Disponível em: http://www.sebrae.com.br. Acesso em: 22 mai. 2012.

SEBRAE - Serviço Brasileiro de Apoio às Micro e Pequenas Empresas. Cadeia produtiva têxtil e de confecções: Cenários econômicos e estudos setoriais. 2008. Disponível em: http://www.sebrae.com.br. Acesso em: 22 mai. 2010.

VASCONCELOS, Christianne Soares Falcão e; Villarouco, Vilma; Soares, Marcelo Márcio. Avaliação Ergonômica do Ambiente Construído: Estudo de caso em uma biblioteca universitária. In: Ação Ergonômica, v. 1, n. 1, 2009.

VILLAROUCO, V. O ambiente está adequado? Anais do ENEAC 2007: I Encontro Nacional de Ergonomia do Ambiente Construído e II Seminário Brasileiro de Acessibilidade Integral. Recife, 2007.

VILLAROUCO, Vilma. An ergonomic look at the work environment. In: Proceeding from IEA 09: 17th World Congress on Ergonomics. China: Beijing, 2009.

VILLAROUCO, Vilma; ANDRETO, Luiz. F. M. Avaliando desempenho de espaços de trabalho sob o enfoque da ergonomia do ambiente construído. In: Produção, v. 18, n. 3, p. 523-539, 2008. 